\title{
Shigellosis in refugees, Austria, July to November 2015
}

I Lederer ${ }^{1}$, K Taus $^{1}{ }^{\text {, F Allerberger }}{ }^{1}$, S Fenkart ${ }^{1}$, A Spina ${ }^{1}$, B Springer ${ }^{1}$, D Schmid ${ }^{1}$

1. Austrian Agency for Health and Food Safety (AGES), Vienna, Austria

Correspondence: Daniela Schmid (daniela.schmid@ages.at)

Citation style for this article:

Lederer I, Taus K, Allerberger F, Fenkart S, Spina A, Springer B, Schmid D. Shigellosis in refugees, Austria, July to November 2015. Euro Surveill.

2015;20(48): pii=30081. DOI: http://dx.doi.org/10.2807/1560-7917.ES.2015.20.48.30081

Article submitted on 27 November 2015 / accepted on 03 December 2015 / published on 03 December 2015

We report on a cluster of shigellosis including 21 cases in refugees and two in local residents who worked in refugee transit centres, detected in Austria in 2015, between calendar weeks 29 and 47. The species isolated from the cluster cases, including one mixed infection, were S. sonnei $(n=13)$, S. flexneri $(n=10)$ and $S$. boydii $(\mathrm{n}=1)$. Eleven of 18 tested isolates were extended spectrum beta-lactamase (ESBL)-positive, including five of six ciprofloxacin-resistant and three azithromycin-resistant isolates.

Since June 2015, there has been an increase in the number of refugees arriving in Austria seeking asylum (monthly average approximately 9,000 [1] or transiting through Austria (approximately one million since July, personal communication, Austrian office, International Organization of Migration, November 2015) to seek asylum elsewhere. We report on the occurrence of 23 cases of shigellosis in 21 refugees and two Austrian residents, identified between 18 July and 18 November 2015 (Figure 1). No cases of shigellosis in refugees were reported before July 2015 .

From January until June 2015,13 cases of shigellosis have been reported among Austrian citizens and 35 cases from July until November; this does not exceed the expected case number compared with 2014. In 2014 in Austria, four cases were identified among nonAustrian citizens from non-European Union (EU) countries i.e. from Serbia and Turkey, respectively.

The cases in refugees presented here were detected during patients' consultation at the medical care facility located in the transit centres (passive case finding) or during the entry health examination at the reception centres, which is compulsory for asylum seekers in Austria (active case finding). Transit centres usually host refugees for a short time (few days), whereas reception centres accommodate asylum seekers for up to several months until long-term housing becomes available. In these centres, there is no screening programme in place for Shigella carriage or other enteric pathogens.
The Table displays the cases by age, date, Austrian province and location of detection, country of origin, epidemiological link and Shigella species with antimicrobial susceptibility. The age distribution among cases was from 1 to 65 years; 16/23 cases were under 10 years old, three cases were in adolescents and four in adults; 15 cases were male. There were 14 cases from Afghanistan including three cases in under fiveyear-olds, five from Syria, including one child under five years old, and two from Iraq.

Three unrelated cases (Case 11, 21 and 23) were each identified in different reception centres, of which one has a syndromic surveillance system in place, including also the syndrome 'watery diarrhoea' (Tyrol: 1 case; Vienna: 2 cases). The remaining 20 cases were identified in eight transit centres (TC) for refugees in six of the nine Austrian provinces (Vienna: 6 cases in 3 TCs; Burgenland and Upper Austria: 4 cases in $1 \mathrm{TC}$, respectively; Lower Austria: 2 cases in 1 TC; Carinthia: 3 cases in 1 TC; Styria: 1 case in 1 TC) (Figure 2). The 21 shigellosis cases in refugees were caused by $S$. sonnei $(n=11)$, S. flexneri $(\mathrm{n}=9)$ and S. boydii $(\mathrm{n}=1)$.

One of the two affected Austrian residents, a professional cleaner (Case 12) developed diarrhoea one day after cleaning a refugee transit centre's toilet using a high-pressure cleaner without wearing personal protective equipment (PPE). This case tested positive for S. sonnei and S. flexneri and was the first known case associated with centre $\mathrm{F}$ (Table). An infection with $S$. sonnei was detected in a translator (Case 16) working at a transit centre; the source of infection for this case is unknown.

Two cases originating from Afghanistan (Cases 1 and 2) were linked by time (i.e. date of detection $\leq$ three days apart) and place (i.e. stay in the same transit center) and positive for $S$. sonnei. Two further cases coming from Afghanistan and Iraq (Cases 3 and 4) were epidemiologically linked, but infected with different Shigella species (Table). Another two cases belonging to one family from Afghanistan (Cases 14 and 15) were infected with S. sonnei. 


\section{FIGURE 1}

Cases of shigellosis in refugees and in two Austrian residents, by calendar week of diagnosis, Austria, 18 July to 18 November $2015(\mathrm{~N}=23)$

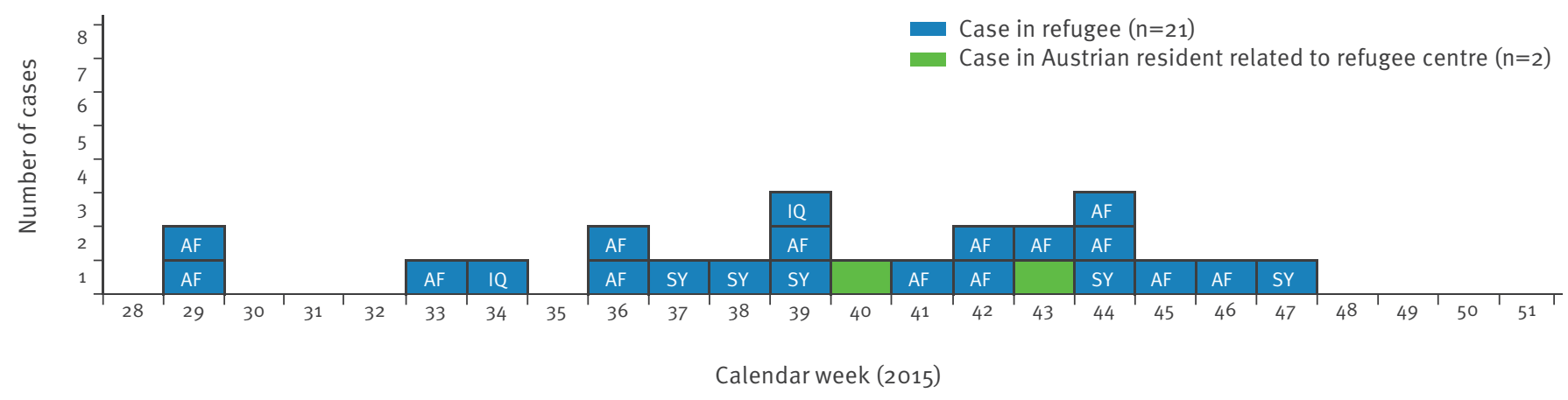

AF: Afghanistan; IQ: Iraq; SY: Syria.

\section{FIGURE 2}

Cases of shigellosis in refugees and two Austrian residents, by location of detection, Austria, 18 July to 18 November 2015 $(\mathrm{n}=23)$

\section{- Cases of shigellosis $(n=23)$}

Refugee reception centres involved $(n=3)$

Refugee transit centres involved $(n=8)$

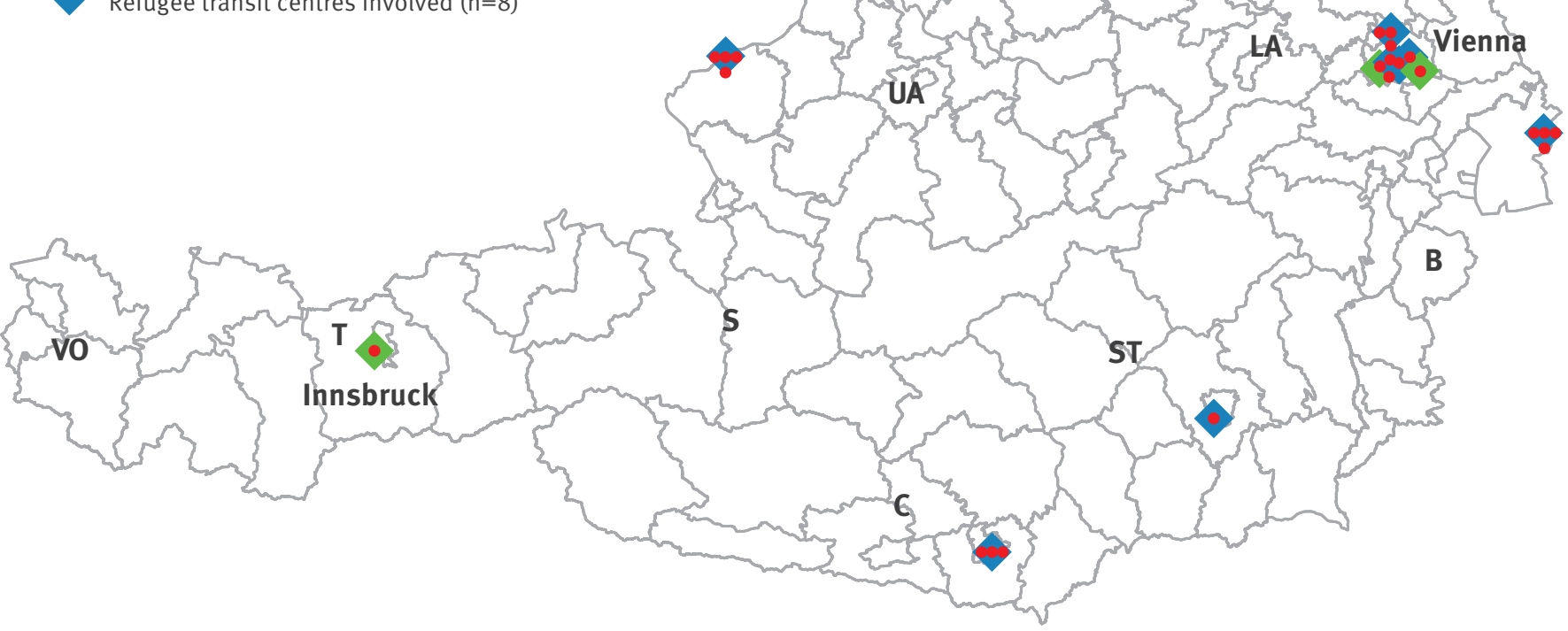

B: Burgenland; C: Carinthia; LA: Lower Austria; S: Salzburg; ST: Styria; T: Tirol; VO: Vorarlberg.

\section{Testing of antimicrobial susceptibility}

A total of 18 Shigella initial isolates were available for in vitro susceptibility testing: nine isolates of $S$. sonnei, eight of S. flexneri and one isolate of S. boydii. Resistance testing was performed on Mueller Hinton E agar (bioMérieux, Marcy l'Etoile) using Etest strips (bioMérieux) as described elsewhere [2]. Of the 18 isolates tested, 11 expressed extended-spectrum betalactamase (ESBL) (S. flexneri 7/8; S. sonnei 3/9; S. boydii 1/1).
Six isolates were resistant to ciprofloxacin. All four ciprofloxacin-resistant S. flexneri isolates were also ESBL-positive, as was the ciprofloxacin-resistant $S$. boydii; the $S$. sonnei isolate resistant to ciprofloxacin was ESBL-negative.

In the absence of criteria for Shigella spp. concerning azithromycin resistance by the European Committee on Antimicrobial Susceptibility Testing (EUCAST), we used criteria published for Salmonella enterica serovar Typhi (resistant: minimum inhibitory concentration (MIC) $\geq 32$ $\mu \mathrm{g} / \mathrm{ml})[3]$. 
Cases of shigellosis in refugees and Austrian residents, working at two transit centres, by age, date, province and location detected, country of origin, Shigella species and resistance, Austria, 18 July to 18 November 2015 (N=23)

\begin{tabular}{|c|c|c|c|c|c|c|c|c|c|c|}
\hline $\begin{array}{l}\text { Case } \\
\text { number }\end{array}$ & $\begin{array}{l}\text { Age } \\
\text { groups } \\
\text { (years) }\end{array}$ & $\begin{array}{l}\text { Date } \\
\text { detected } \\
(2015)\end{array}$ & $\begin{array}{l}\text { Province } \\
\text { detected }\end{array}$ & $\begin{array}{l}\text { Location } \\
\text { detected }\end{array}$ & $\begin{array}{c}\text { Country of } \\
\text { origin }\end{array}$ & $\begin{array}{l}\text { Epidemiological } \\
\text { link with }\end{array}$ & Case finding & Shigella species & ESBL & $\begin{array}{l}\text { Resistance to } \\
\text { Ciprofloxacin/ } \\
\text { Azithromycin }\end{array}$ \\
\hline 1 & $15-20$ & $18 \mathrm{Jul}$ & Burgenland & TC A & Afghanistan & Case 2 & Passive & S. sonnei & $\mathrm{Neg}$ & No/No \\
\hline 2 & $15-20$ & $19 \mathrm{Jul}$ & Burgenland & TC A & Afghanistan & Case 1 & Passive & S. sonnei & $\mathrm{Neg}$ & No/No \\
\hline 3 & $5-10$ & 14 Aug & $\begin{array}{l}\text { Lower } \\
\text { Austria }\end{array}$ & TC B & Afghanistan & Case 4 & passive & S. flexneri & Pos & No/No \\
\hline 4 & $5-10$ & 17 Aug & $\begin{array}{l}\text { Lower } \\
\text { Austria }\end{array}$ & TC B & Iraq & Case 3 & Passive & S. sonnei & $\mathrm{Neg}$ & Yes/No \\
\hline 5 & $<5$ & 31 Aug & Burgenland & TC A & Afghanistan & None & Passive & S. flexneri & Pos & Yes/No \\
\hline 6 & $5-10$ & o6 Sep & Vienna & TC D & Afghanistan & None & Passive & S. flexneri & Pos & No/No \\
\hline 7 & $20-50$ & 12 Sep & Burgenland & TC A & Syria & None & Passive & S. flexneri & Pos & No/Yes \\
\hline 8 & $<5$ & $17 \mathrm{Sep}$ & Vienna & TC C & Syria & None & Passive & S. flexneri & Pos & Yes/Yes \\
\hline 9 & $5-10$ & $23 \mathrm{Sep}$ & Vienna & TC D & Syria & None & Passive & S. sonnei & Pos & No/No \\
\hline 10 & $5-10$ & 23 Sep & Vienna & TC E & Afghanistan & None & Passive & S. boydii & Pos & Yes/Yes \\
\hline 11 & $15-20$ & $24 \mathrm{Sep}$ & Vienna & $\mathrm{RC}_{1}$ & Iraq & None & Active & S. flexneri & Pos & Yes/No \\
\hline 12 & $20-50$ & $30 \mathrm{Sep}$ & Carinthia & TC F & Austria & None & Passive & $\begin{array}{l}\text { S. flexneri/ } \\
\text { S. sonnei }\end{array}$ & $\begin{array}{l}\text { Pos/ } \\
\text { pos }\end{array}$ & Yes/No \\
\hline 13 & $5-10$ & $080 \mathrm{ct}$ & $\begin{array}{l}\text { Upper } \\
\text { Austria }\end{array}$ & TC H & Afghanistan & None & Passive & S. sonnei & NA & NA \\
\hline 14 & $<5$ & 17 Oct & $\begin{array}{l}\text { Upper } \\
\text { Austria }\end{array}$ & TC H & Afghanistan & Case 15 & Passive & S. sonnei & NA & NA \\
\hline 15 & $5-10$ & $17 \mathrm{Oct}$ & $\begin{array}{l}\text { Upper } \\
\text { Austria }\end{array}$ & TC H & Afghanistan & Case 14 & Passive & S. sonnei & NA & NA \\
\hline 16 & $\leq 65$ & $210 \mathrm{Ct}$ & Vienna & TCE & Austria & None & Passive & S. sonnei & Pos & No/No \\
\hline 17 & $<5$ & $250 \mathrm{ct}$ & Styria & TC G & Afghanistan & None & Passive & S. sonnei & $\mathrm{Neg}$ & No/No \\
\hline 18 & $5-10$ & 26 Oct & Carinthia & TC F & Syria & None & Passive & S. sonnei & $\mathrm{Neg}$ & $\mathrm{No} / \mathrm{No}$ \\
\hline 19 & $5-10$ & 29 Oct & Vienna & TC D & Afghanistan & None & Passive & S. sonnei & $\mathrm{Neg}$ & No/No \\
\hline 20 & $20-50$ & $300 \mathrm{ct}$ & $\begin{array}{c}\text { Upper } \\
\text { Austria } \\
\end{array}$ & TC H & Afghanistan & None & Passive & S. flexneri & NA & NA \\
\hline 21 & $5-10$ & $06 \mathrm{Nov}$ & Tyrol & $\mathrm{RC} 2$ & Afghanistan & None & Active & S. sonnei & NA & NA \\
\hline 22 & $5-10$ & 12 Nov & Carinthia & TC F & Afghanistan & None & Passive & S. flexneri & NA & NA \\
\hline 23 & $5-10$ & 18 Nov & Vienna & $\mathrm{RC}_{3}$ & Syria & None & Active & S. flexneri & Neg & $\mathrm{No} / \mathrm{No}$ \\
\hline
\end{tabular}

NA: not available; Neg: negative; Pos: positive; RC: reception centre; TC: transit centre.

Of the 18 isolates tested, three (S. flexneri, $(n=2)$ from Syrian refugees; S. boydii $(n=1)$ from an Afghan refugee) showed resistance against azithromycin (all in addition to their ESBL positivity, and two in addition to ciprofloxacin resistance).

\section{Discussion and conclusion}

Shigellosis is an acute infection of the intestine caused by bacteria of the genus Shigella, i.e. S. dysenteriae, $S$. flexneri, S. boydii and S. sonnei [4]. In the World Health Organization (WHO) Eastern Mediterranean Region, shigellosis is recognised as one of the major causes of persistent diarrhoea $[5,6]$. Epidemics of shigellosis have repeatedly affected sub-Saharan Africa, Central America and south/south-east Asia, often hitting areas of political upheaval and natural disaster [7]. In western European countries transmission is limited to groups with close contact often with a primary case infected during foreign travel. Refugees are at increased risk of infectious disease primarily due to their vulnerability, poor hygiene condition, and overcrowding in reception or transit centres. Shigellosis is a well-known problem in these settings [8-10]. We discovered high rates of antimicrobial resistance in all Shigella species isolated from the recently arrived refugees, which physicians should be aware of. Azithromycin is recommended by the American Academy of Paediatrics for treatment of shigellosis in children and by the WHO as a second-line treatment in adults [7]. So far, the intercontinental spread of azithromycin-resistant Shigella mainly affected men who have sex with men [11-13]. The acquisition and expression of ESBLs is not unusual for Shigella. Our findings on ESBL-positivity in 11 of 18 tested isolates from refugees originating from Afghanistan, Iraq and Syria make antimicrobial susceptibility testing in this population indispensable.

In Austria in 2015, an additional 40 S. sonnei isolates were documented without any known refugee-association; only five of them were ESBL-producing; 13 were 
resistant to ciprofloxacin, including one ESBL-positive isolate. Of $11 \mathrm{~S}$. flexneri isolates documented without refugee-association, none showed ESBL-production; three were resistant to ciprofloxacin. None of two $S$. boydii isolates without refugee-association produced ESBL.

The occurrence of shigellosis cases in refugees is not unexpected with regards to limited personal hygiene and proper sanitary facilities. The incubation period of shigellosis ranges from one to three days, suggesting that infectious exposure occurred shortly before entering Austria or in the Austrian refugee centres. Nevertheless, the sources of infections remain unknown. The occurrence of Shigella infections in a native Austrian cleaner and a translator indicates that clinicians should be aware of the possibility of secondary cases of shigellosis in Austrians. However, the risk of infection for persons caring for refugees is considered low when appropriate hygiene measures, such as hand hygiene or PPE, are applied.

Shigellosis among refugees has previously been observed in similar settings globally $[10,14,15]$. Carriers and infected persons who do not clean their hands thoroughly with water and soap after defecation are the main source of Shigella spread. With the arrival of the northern hemisphere winter, risks posed by pathogens, whose spread is facilitated by overcrowding, insufficient sanitary facilities and lower temperatures will increase [16]. Unless hygiene measures are sufficiently applied in transit centres and reception centres, more cases of shigellosis may be observed among refugees who have recently arrived in the EU. Therefore, an organised effort to promote personal hygiene concurring with refugees' cultural practice, such as washing after defecation or use of particular types of latrines, is the most important control measure to decrease faecal-oral transmission in refugee centres. In addition, it is important to keep in mind that according to a recent risk assessment published by the European Centre for Disease Prevention and Control (ECDC), 'refugees are vulnerable to infectious diseases because of the specific circumstances under which they live and therefore they require special attention' [17].

\section{Conflict of interest}

None declared.

\section{Authors' contributions}

Ingeborg Lederer and Burkhard Springer provided laboratory expertise; Karin Taus, Sabrina Fenkart and Alexander Spina collected and analysed epidemiological data; Daniela Schmid and Franz Allerberger wrote the manuscript. of refugees]. Vienna: Parliamentary Administration; 2015. German. Available from: https://www.parlament.gv.at/ ZUSD/BUDGET/BD_-_Anfragebeantwortung_zu_steigenden_ Fluechtlingszahlen.pdf

2. Stürenburg E, Sobottka I, Noor D, Laufs R, Mack D. Evaluation of a new cefepime-clavulanate ESBL Etest to detect extendedspectrum beta-lactamases in an Enterobacteriaceae strain collection.J Antimicrob Chemother. 2004;54(1):134-8. DOI: 10.1093/jac/dkh274 PMID: 15150168

3. Parry CM, Thieu NT, Dolecek C, Karkey A, Gupta R, Turner P, et al. Clinically and microbiologically derived azithromycin susceptibility breakpoints for Salmonella enterica serovars Typhi and Paratyphi A. Antimicrob Agents Chemother. 2015;59(5):2756-64. DOI: 10.1128/AAC.04729-14 PMID: 25733500

4. Heymann DL. Control of Communicable Diseases manual. 2oth Edition. American Public Health Association, Washington 2015.

5. Gargouri N, Walke H, Belbeisi A, Hadadin A, Salah S, Ellis A, et al. Estimated burden of human Salmonella, Shigella, and Brucella infections in Jordan, 2003-2004. Foodborne Pathog Dis. 2009;6(4):481-6. DOI: 10.1089/fpd.2008.0192 PMID: 19415972

6. Lichnevski M. Shigella dysentery and shigella infections. East Mediterr Health J. 1996;2(1):102-6.

7. World Health Organization (WHO). Guidelines for the control of shigellosis, including epidemics due to Shigella dysenteriae type 1. ISBN: 9241592330. Geneva: WHO. 2005. Available from: http://apps.who.int/iris/bitstream/10665/43252/1/92415933 oX.pdf?ua $=1 \& u a=1$

8. Kjersem H, Jepsen S, Larsen L, Black F. Salmonella and Shigella carriers among refugees from the middle east and Sri Lanka in Denmark.Scand J Soc Med. 1990;18(3):175-8.PMID: 2237324

9. European Centre for Disease Prevention and Control (ECDC). Infectious diseases of specific relevance to newly-arrived migrants in the EU/EEA. Stockholm; ECDC: 19 Nov 2015. Available from: http://ecdc.europa.eu/en/publications/ Publications/Infectious-diseases-of-specific-relevance-tonewly-arrived-migrants-in-EU-EEA.pdf

10. Benny E, Mesere K, Pavlin BI, Yakam L, Ford R, Yoannes M, et al. A large outbreak of shigellosis commencing in an internally displaced population, Papua New Guinea, 2013. Western Pac Surveill Response J. 2014;5(3):18-21. DOI: 10.5365/ wpsar.2014.5.2.003 PMID: 25648967

11. Centers for Disease Control and Prevention (CDC), Bowen A, Eikmeier D, Talley P, Siston A, Smith S, Hurd J, et al. . Notes from the Field: Outbreaks of Shigella sonnei Infection with Decreased Susceptibility to Azithromycin Among Men Who Have Sex with Men - Chicago and Metropolitan Minneapolis-St. Paul, 2014.MMWR Morb Mortal Wkly Rep. 2015;64(21):597-8. PMID: 26042652

12. Gaudreau C, Barkati S, Leduc JM, Pilon PA, Favreau J, Bekal $\mathrm{S}$. Shigella spp. with reduced azithromycin susceptibility, Quebec, Canada, 2012-2013.Emerg Infect Dis. 2014;20(5):8546. DOI: 10.3201/eid2005.130966 PMID: 24750584

13. Baker KS, Dallman TJ, Ashton PM, Day M, Hughes G, Crook PD, et al. Intercontinental dissemination of azithromycin-resistant shigellosis through sexual transmission: a cross-sectional study. Lancet Infect Dis. 2015;15(8):913-21. DOI: 10.1016/S14733099(15)00002-X PMID: 25936611

14. Henze B. [Endemic occurrence of bacillary dysentery among refugees and the native population]. Offentl Gesundheitsdienst. 1959;21:139-48. German.PMID: 14401166

15. Kjersem H, Jepsen S, Larsen L, Black F. Salmonella and Shigella carriers among refugees from the middle east and Sri Lanka in Denmark.Scand J Soc Med. 1990;18(3):175-8.PMID: 2237324

16. European Centre for Disease Prevention and Control (ECDC) Communicable disease risks associated with the movement of refugees in Europe during the winter season. Stockholm: ECDC; 10 Nov 2015. Available from: http://ecdc.europa.eu/ en/publications/Publications/refugee-migrant-health-ineuropean-winter-rapid-risk-assessment.pdf

17. European Centre for Disease Prevention and Control (ECDC). Rapid Risk Assessment. Shigellosis among refugees in the EU. Stockholm: ECDC. 26 Nov 2015. Available from: http://ecdc. europa.eu/en/publications/Publications/Shigella-RRA-24-112015-Austria-Greece-Slovenia.pdf

\section{References}

1. Budget Service of the Republic of Austria. [Request reply of the Budget Service: Question by Mr Ing. Robert Lugar (club chairman Team Stronach) to the increasing number 